\title{
La pérdida de Castelnuovo en 1539 según fuentes españolas
} The loss of Castelnuovo in 1539 according to the Spanish sources

\author{
Ricardo GONZÁLEZ CASTRILLO \\ Universidad Rey Juan Carlos \\ ricardo.gonzalez@urjc.es
}

Recibido: mayo 2012

Aceptado: marzo 2013

\section{RESUMEN}

Entre las acciones de guerra llevadas a cabo por Jayr al-Dīn Barbarroja, señor de Argel y corsario al servicio del Gran Turco, sobresale la toma de Castelnuovo en 1539, localidad situada en la costa dálmata de Albania. La reconquista turca de esta plaza -llevada a cabo entre los meses de julio y de agosto de ese año- ha sido narrada por varios cronistas con mayor o menor extensión y detalle, los cuales siempre destacaron la valerosa defensa de la ciudad que hicieron los españoles pese a su número reducido. El presente artículo recoge los testimonios incluidos en las fuentes acerca de la caída de Castelnuovo. Tras la misma, Carlos V procuró el rescate de los cautivos ante Barbarroja, a través del contador Juan Gallego.

Palabras clave: Castelnuovo, toma de Castelnuovo, 1539, Barbarroja, Jayr al-Dīn.

\begin{abstract}
Among the military actions carried out by Jayr al-Dīn Barbarossa, at the same time Lord of Alger and corsair under the service of the Great Turk, the conquest in 1539 of Castelnuovo, a town located on the Dalmatian coast of Albania, stands out over the others. The Turkish reconquest of this town, that took place between the months of July and August of that year, has been related by several chroniclers with more or less extension and details in their works. However, all of them remark the brave defense of the town done by the Spanish soldiers in spite of their small number. This article gathers the testimonies on the fall of Castelnuovo included in the Spanish manuscripts and in printed sources. After the military action was finished, the king Charles the Fifth attempted to rescue the captives of Castelnuovo from the pirate Barbarrosa, through the counter Juan Gallego, who negotiated a possible agreement with the Turkish corsair.
\end{abstract}

Keywords: Castelnuovo, conquest of Castelnuovo, 1539, Barbarossa, Jayr al-Dīn.

SUMARIO: 1. Introducción, 2. La Santa Liga, 3. Derrota de la Liga en Prevesa y conquista cristiana de Castelnuovo, 4. Reconquista turca de Castelnuovo, 5. Espionaje turco durante el asedio, 6. Desastre final, 7. Supervivientes, 8. Conclusiones. 


\section{INTRODUCCIÓN}

El enclave mediterráneo de Castelnuovo -actual Herceg Novi- en la costa dálmata de Albania, jugó un destacado papel en la lucha que mantuvo la Cristiandad durante el siglo XVI con el imperio otomano y, más concretamente, el emperador Carlos V con el sultán Solimán el Magnífico, y su gran almirante Jayr al-Dīn Barbarroja, señor de Argel.

En Castelnuovo protagonizaron las tropas españolas en ese año 1539 una de las más gloriosas hazañas en su enfrentamiento contra el poder turco. Sin embargo, su recuerdo no ha sido suficientemente enaltecido y el olvido ha acabado por oscurecer la grandeza de la acción, hasta el punto de que hay quien llega incluso a confundir la fecha en que ocurrió ${ }^{\text {. }}$

Francisco López de Gómara, el cronista de los hermanos Barbarroja- Arūy, Jayr al-Dīn e Isḥāq-, renegados griegos oriundos de Mitilene, sitúa Castelnuovo "en Esclavonia, çerquita de Cataro" y afirma que "tiene un muy grandísimo puerto y muy seguro" ${ }^{2}$. Este autor deja traslucir su admiración hacia el segundo de los hermanos citados al describirlo como "el mayor cosario y mejor capitan de mar que jamas ha habido y que mas y mejores cosas ha hecho sobre agua" 3 .

\section{LA SANTA LIGA}

El peligro turco y la necesidad de presentar una fuerza unida frente a él, hizo que en 1538 el Papa Paulo III, el emperador Carlos V y su hermano Fernando I de Austria, Rey de Romanos, así como la república de Venecia decidieran constituir la Santa Liga ${ }^{4}$. El compromiso de los coaligados quedó estipulado en las capitulaciones firmadas el 8 de febrero de ese año: el Papa se obligaba a costear "la sexta parte de todo el gasto que se hiziere" en esta guerra; el emperador "contribuira tres sextas partes, que es la mitad de todo el gasto"; y Venecia "ofrescio y prometio las dos sextas partes, que es la tercia parte de toda la expensa y gasto"s. En cuanto a Fernando I de Austria, no se le exigía aportación alguna. Solo mantendría un ejército en Hungría contra los otomanos, "porque assay le bastan sus gastos tan grandes que siempre haze contra turcos".

La fuerza prevista para tal empresa era de "dozientas galeras e cien naos gruessas: e cincuenta mill infantes a pie". Treinta y seis de cuyas galeras corría de cuenta de $\mathrm{Su}$ Santidad el armarlas y sustentarlas, mientras que Carlos V y la Señoría harían lo

${ }^{1}$ GARCÍA SALINERO, Fernando (ed.), Viaje de Turquia, Madrid, Cátedra, 2000, p. 250, nota 29 sitúa en 1538 este suceso.

${ }^{2}$ LÓPEZ DE GÓMARA, F., “Crónica de los Barbarroja”, Memorial Histórico Español, t. VI (1853), p. 427.

${ }^{3}$ Ibidem., p. 439.

${ }^{4}$ De esta Liga "se escusó el rey de Françia por su amistad con el Turco". Relación del Reynado del Emperador Carlos $5^{\circ}$. Real Bibliorteca de Madrid, ms. II-1273, f. 159r.

${ }^{5}$ DIAZ DE TANCO, V., Libro intitulado Palinodia, de la nephanda y fiera nación de los Turcos. Orense, imp. por el autor, 1547, f. lx v.

${ }^{6}$ Ibidem., f. lxj r. 
mismo con otras ochenta y dos cada uno . Y quedó establecido que "los capitanes generales de esta santa expedición sean los ylustrissimos varones Francisco Maria, duque de Urbino, por tierra e Andrea Doria, príncipe de Melpha, por mar"s.

Suscribieron el acuerdo los representantes de las potencias implicadas: Juan Fernández Manrique, marqués de Aguilar, por parte del emperador y de su hermano; y Marco Antonio Contareno, por el senado de Venecia. "E ansi lo firmaron de sus nombres por si y en nombre de los señores sobredichos". Una de las cláusulas que incluía la constitución de esta Liga precisaba que "era para Venecianos las tierras que se tomassen al Turco en Esclauonia y Grecia o en sus islas" ${ }^{10}$, lo cual, como se verá más adelante, fue incumplido luego por Gonzaga y Doria.

\section{DERROTA DE LA LIGA EN PREVESA Y CONQUISTA CRISTIANA DE CASTELNUOVO}

La actuación de la Santa Liga tuvo un mal comienzo con el funesto suceso de Prevesa, cuyo resultado "fue más bien una derrota", en palabras de Brandi". Y para contrarrestar tal fracaso decidieron las fuerzas coaligadas conquistar a los turcos el enclave de Castelnuovo, "un lugar en el golfo de Cataro o Rizano, poco fuerte avnque con vn valuarte házia la mar, y vn castillo sobre peña que guardauan 350 . Turcos. Los naturales son Esclauones..." ${ }^{12}$. No obstante presentarlo como "lugar poco fuerte", Sandoval afirma que los turcos "auian fortificado a Castilnouo el año antes sabiendo la liga" ${ }^{13}$. Vicente Rocca, por su parte, lo describe como "vn lugar maritimo... d' hasta quatrozientos vezinos, el qual tiene dos castillos, vno a la orilla del agua, y el otro sobre la tierra en vn alto" ${ }^{14}$.

El 23 de octubre de 1538 arribó la armada de la Santa Liga, "que eran 140 galeras y 72 velas quadras" ${ }^{15}$, a la boca del golfo de Cataro y el 26 emplazaron la

${ }^{7}$ Ibidem., f. $1 \mathrm{x}$ v.

${ }^{8}$ Ibidem., f. lxj r. Al fallecer el duque de Urbino -a quien Sepúlveda llama Giovanni Maria- fue designado Ferrante Gonzaga, virrey de Sicilia, para sustituirle. Integraban también el cuadro de mandos de la Liga Marco Grimani, patriarca de Aquileya, como capitán de la armada del Papa, y Vincenzo Capelo, de la veneciana. SEPÚLVEDA, Juan Ginés de, "Historia de Carlos V", en CAPELA REAL, J. y otros (eds.), Obras completas, Pozoblanco, Ayuntamiento, 1995-2010, t. XII (2008), p. 43; y DOLCE, L., Vida de Carlos V [trad. Alfonso de Ulloa]. Real Biblioteca de Madrid, ms. II-2795, f. 61v.

${ }^{9}$ DIAZ DE TANCO, op. cit., f. lx r-v. El texto latino de este acuerdo puede verse en GIRÓN, Pedro, Crónica del emperador Carlos V, Madrid, CSIC, 1964, pp. 248-252.

${ }^{10}$ SANDOVAL, Prudencio de, Historia de la vida y hechos del emperador Carlos V, Pamplona, Bartholome Paris, 1614, p. 351a.

${ }^{11}$ BRANDI, C., Carlos V, Madrid, Ed. Nacional, 1943, p. 345.

${ }^{12}$ SANDOVAL, op.cit., p. 354b.

${ }^{13}$ Ibidem.

${ }^{14}$ ROCCA, V., Hystoria en la qual se trata de la origen y guerras que han tenido los Turcos, Valencia, 1555 , f. CIX va.

${ }^{15}$ Archivo General de Simancas (AGS), Estado, leg. 1314, f. 28, en LAIGLESIA, F. de la, Estudios Históricos (1515-1555), Madrid, 1908, p. 546 y ss. 
artillería que sacaron del galeón del príncipe Doria, comenzando los españoles a batir "por la parte de tierra, y por la parte del mar el general de venecianos con sus galeras". E hicieron tal estrago en la muralla que venecianos y españoles "pudieron darla asalto", y los turcos corrieron a refugiarse en los castillos ${ }^{16}$. Finalmente, acabaron "rindieronse de ay en tres días los del valuarte a Vicente Capelo, y los del castillo a don Hernando [Gonzaga]", con el compromiso -que luego no se cumplióde que los turcos podrían ser rescatados en Ragusa a razón de 40 ducados.

El número de prisioneros capturados en esta acción fue de $1.600^{17}$. Vicente Capelo reclamó la plaza en nombre de Venecia, según lo acordado al constituirse la Liga, pero ni Doria ni Gonzaga estuvieron conformes en ello" ${ }^{18}$. Y nombraron a Francisco Sarmiento, maestre de campo, que quedasse allí en guarnicion con ciertas compañías, en los quales auia hasta tres mil españoles, los mas arcabuzeros, todos soldados viejos y luzidos, o según otro dos mil y quinientos... de manera que toda la guarnicion fue de españoles"19.

Vicente Rocca cifra en "cerca de quatro mil Españoles, los mas dellos arcabuzeros", el contingente de tropas dejado a Sarmiento ${ }^{20}$, mientras la crónica de Antonio Doria habla de "tres mill soldados hespañoles" a los cuales prometieron "Andrea Doria y el Gonçaga que los sacarían de allí a la primauera" ${ }^{21}$. De tales palabras podría deducirse, quizá, que la intención de los coaligados no era la de prolongar demasiado tiempo el dominio sobre Castelnuovo. De ahí que en las instrucciones que Doria y Gonzaga dejaron a Sarmiento antes de abandonarlo, en documento fechado el 17 de noviembre de 1538 que guarda el Archivo General de Simancas, se le indica que "agora no se han de hazer otras labores ni reparos de nuevo sino aquellos que no se pueden escusar y que basten para entretenerse este invierno" 22 .

Pese a las órdenes recibidas, en previsión de un futuro cerco que los turcos pudieran poner a Castelnuovo, posibilidad que Francisco Sarmiento, "como capitan prudente siempre lo temiò... procurò de fortalecerse desde el principio, trabajando con los soldados en hazer valuartes, abrir fosos y otros reparos, en los ocho meses o nueue que tuuo de espacio"23. A tenor de estas palabras, carecería de fundamento el reproche que

${ }^{16}$ AGS, Estado, leg. 17, en LAIGLESIA, op.cit., p. 549.

${ }^{17}$ SANDOVAL, op.cit., p. $355 \mathrm{a}$.

${ }^{18}$ Meses después, Carlos V pretendió entregar Castelnuovo a los venecianos, siempre que éstos "pagassen lo que toca de los gastos" hechos hasta el momento por los españoles "en conseruaçion de aquella fuerça". El marqués de Aguilar escribía al emperador, con fecha 22 de junio de 1539, acerca de las negociaciones en curso que llevaban a cabo sobre este asunto don Lope de Soria, el embajador veneciano y el Papa. AGS, Guerra Antigua, leg. 15, doc. 85.

19 Ibidem. Según precisa Sepúlveda, Sarmiento era "vecino y regidor de Burgos". Vid. SEPÚLVEDA, op.cit., p. 49.

${ }^{20}$ ROCCA, op.cit., f. CIX va.

${ }^{21}$ DORIA, A., Compendio de los sucesos que en la vida del emperador Carlos Quinto de gloriosa memoria acontecieron [trad. Luis de Toro], Biblioteca Nacional de Madrid (BNE), ms. 1608, p. 167.

${ }^{22}$ AGS, Guerra, leg. 13, en LAIGLESIA, op.cit., pp. 565 y s.

${ }^{23}$ SANDOVAL, op.cit., p. 375a. 
López de Gómara hace a la conducta de Francisco Sarmiento, en el sentido de "no fortificarse muy bien en casi un año que tuvo de tiempo", al cual acusa, además, de no haber querido entregar la plaza a los venecianos cuando la reclamaron y negarse luego a abandonarla "como el Emperador lo mandaba" ${ }^{24}$. En todo caso, aunque hubiese pecado de imprevisión, en realidad no habría hecho más que atenerse a las órdenes recibidas.

\section{RECONQUISTA TURCA DE CASTELNUOVO}

Ciertamente, la pérdida de Castelnuovo pesaba mucho en el ánimo de Solimán I. Por ello, apenas transcurridos los meses de invierno, "ordeno que el exercito de tierra y Barbarroxa con el armada de la mar fuesen a cobrarle" 25 . Mandaba el ejército en esta ocasión Ulamen, el cual "junto para la empressa treynta mil infantes con la caualleria necessaria y con siete sansacos y otro gran numero de morlacos y cimerotes y otras gentes saluages y pobres, mas para mucho trabajo" mientras Barbarroja armaba una gran flota en la que "embarcò diez mil turcos y quatro mil ianizaros"

Treinta de sus galeotas las envió como avanzada al mando de "Zinan Iudio o, según otros, con Dragut y Zefut, para que se pusiesen a la entrada del golfo de Cataro". Y de ellas saltaron a tierra mil turcos en la mañana del 12 de julio de 1539 "a tomar agua y a reconocer el pueblo y campo". Pero fueron obligados a reembarcar por el ataque de los españoles mandados por Machín de Munguía y otros dos capitanes, además de Lázaro Coron al frente de la caballería albanesa. En la tarde de ese mismo día, nuevamente volvieron a desembarcar los turcos con más gente en busca de agua, sufriendo la pérdida de 300 de sus hombres ante el ataque de 600 españoles con Francisco Sarmiento a la cabeza y los capitanes Álvaro de Mendoza, Olivera y Juan Vizcaíno, quienes sólo tuvieron 12 bajas ${ }^{27}$.

Barbarroja llegó a Castelnuovo el 18 de julio "con mayor armada que se pensaua, y començò luego a echar gente y artillería en tierra. Llegò luego Vlamen con el exercito"28. Empezaba así la reconquista turca de Castelnuovo, narrada por varios cronistas de la época con mayor o menor extensión y detalle, pero resaltando siempre la valerosa defensa de la plaza que hicieron los españoles. Prudencio de Sandoval da un pormenorizado relato de los diferentes hechos de armas que tuvieron lugar desde la llegada de los primeros contingentes turcos hasta el desastre definitivo del 7 de agosto. Y consigna además que Francisco Sarmiento no dejó de

${ }^{24}$ LÓPEZ DE GÓMARA, op.cit., p. 429.

${ }^{25}$ DORIA, op.cit., p. 168.

${ }^{26}$ SANDOVAL, op.cit., p. 373b. Este cronista indica además que Ulamen era de origen persa y de gran experiencia en la guerra. Abandonó el servicio del Sofi para pasarse a las filas del Gran Turco, el cual le nombró gobernador de Bosnia. Para conocer el coste de la campaña, IMBER, C. H.: "The cost of naval warfare", Archivum Ottomanicum, t. IV (1972), pp. 203-216.

${ }^{27}$ SANDOVAL, op. cit, pp. 373b-374a.

${ }^{28}$ Ibidem. El mismo Sandoval apunta que, en cierto momento de la lucha, Barbarroja llegó a ofrecer "dos pagas a los españoles y nauios en que se fuesen, si le dauan el lugar, aunque algunos dizen que fue al principio esto" (pp. 375b-376a). 
enviar mensajeros con peticiones de socorro a España, Sicilia y Brindisi, "donde estaua con las galeras Andrea Doria, pero de ninguna parte se lo embiaron" ${ }^{29}$.

Es de resaltar el interés de este cronista por mencionar los nombres de quienes escribieron en Castelnuovo una de las páginas más heroicas de la Historia, para que su hazaña no quedara en el olvido. A tal fin, cita a cada uno de los capitanes de las quince banderas que componían la guarnición de la plaza al iniciarse el asedio, cuyo total era de "menos de tres mil soldados". Y señala asimismo que había también en el lugar "mil moços y mugeres,... quarenta mercaderes y clerigos con Ieremias Ginoues...obispo,... ciento y cinquenta capeletes de cauallo con el capitán Lazaro de Coron, y otros muchos griegos, con el cauallero George y con Andres Escrapula y otros capitanes, y todos gente que tenia honra" ${ }^{30}$.

La caída de Castelnuovo ha sido narrada también, con amplitud, por un testigo presencial del suceso, "un christiano que fue esclavo del sant jaco ${ }^{31}$ de Castilnouo que huyo de los turcos quando la presa del dicho lugar y ha venido a Veneçia", cuyo relato figura inserto en la Crónica de Pedro Girón ${ }^{32}$. Según el mismo, el 15 de julio "allegaron sota Castilnouo. clx. galeras, fustas y bergantines turquescos", de los que salieron muchos hombres para "ruynar las viñas y tomar agua", pero fueron obligados a reembarcar por los defensores de la plaza, "que prendieron. xvj. y mataron tantos que segund la sangre corria paresçia auer muerto çinquenta toros". Una nueva incursión otomana fue también rechazada luego por los sitiados, quienes "dieronles otra mano muy peor que la primera".

La llegada de Barbarroja ante Castelnuovo se produjo, según este narrador, el 17 de julio, un día antes, por tanto, de lo que indica Sepúlveda. Y lo hizo al frente de una escuadra de "hasta dozientas belas". Curiosa es la apología de los soldados españoles que pone en boca de Barbarroja ante las quejas de sus gentes por las pérdidas sufridas hasta entonces. "Sabed -les dice- que los soldados que están en Castilnouo son los mejores que tiene el emperador Carlos en todos sus reynos. Estos son los que tomaron preso al Papa y rey de Françia, y los que prendieron a Coron y me echaron de Tunez y ganaron aquel reyno y la armada que yo lleuaua. Y son los que han hecho los mayores hechos y hazañas que se pueden contar. No creais que ellos se rendiran ansi porque son fieles y valientes".

Después de recriminar al "santjaco del ducado de Castilnouo y aquella comarca de la Morlachia, llamado Baliber... con henojo y algunas malas palabras", por haber

${ }^{29}$ SANDOVAL, op.cit., p.375a. Es más, el almirante, en carta dirigida al emperador el 6 de agosto, menosprecia la llamada de socorro de Sarmiento al opinar que "ha sido solamente para poderse mejor justificar y cumplir con su honra si algund partido hiciere con los enemigos". AGS, Estado, leg. 4, en LAIGLESIA, op.cit., pp. 579-584.

${ }^{30}$ SANDOVAL, op.cit., p. $375 \mathrm{a}$.

${ }^{31}$ Los sanjacos eran "los gouernadores de las prouincias: y capitanes de gran fausto". DIAZ DE TANCO, op.cit., f. lvj ra.

${ }^{32}$ Biblioteca Nacional de Madrid (BNE), ms. 3825, ff. 178r-181v; GIRÓN, op.cit., pp. 326-332. 
dicho que tenía la situación bajo control cuando no era así, "hizo sacar de la armada treynta y dos pieças de artillería y meterlas" en los bastiones. Y desde ese día -24 de julio- hasta su pérdida, "batieron los turcos la dicha plaça por tierra con las dichas treynta y dos pieças, y por mar con muchas mas que estauan en las galeras".

\section{ESPIONAJE TURCO DURANTE EL ASEDIO}

El esclavo confidente señala que, en cierta ocasión, fue al campo turco a requerimiento de Francisco Sarmiento, para conocer cuáles eran los bastiones más débiles y poder informarle, a fin de que pudiera "dalles alguna mala mano". "Y con çiertas señales le auiso a donde podía yr". Salió entonces el capitán Machín de Munguía con 150 soldados e "hizieron cruel matança" en el bastión indicado por el esclavo, consiguiendo además que los turcos de otros bastiones y el propio Barbarroja iniciaran una retirada "pensando que todos los españoles auian salido de Castilnouo para saltearlos". Pero avisado a tiempo el corsario de que "los christianos heran pocos", arremetió contra ellos y les obligó a refugiarse dentro de las murallas, desde donde los arcabuceros con sus disparos mataron a buen número de turcos, entre ellos, "el rey de Tejora, que tenia su estado cerca de Tripol de Berueria".

Una vez más se constata, pues, el decisivo papel que en los diferentes encuentros de la Cristiandad con los turcos jugaron las informaciones proporcionadas por los espías de uno y otro bando, que cambiaron a veces el curso de la guerra ${ }^{33}$. En el caso concreto de Castelnuovo, Prudencio de Sandoval refiere la información dada a Barbarroja por "un iudio de Napoles, ropauegero" o, según otros, "por vn artillero esclauon", aconsejándole concentrar el fuego de la artillería sobre el castillo alto.

Atendió el corsario la sugerencia batiendo durante "cinco días sin parar las noches hasta que no dexo piedra sobre piedra del castillo", gracias a lo cual pudieron hacerse los turcos con aquella fortaleza, obligando a los defensores a buscar refugio en el castillo bajo. El mismo Sepúlveda anota otro caso de traición: el protagonizado por tres sujetos -Ocaña, Cortinas y el portugués Velázquez- que se pasaron al enemigo y animaron a Barbarroja a mantenerse firme "porque ya los españoles eran pocos" y se encontraban malheridos ${ }^{34}$.

Vicente Rocca recoge también en su obra la traición de "vn vellaco moreno de Ocaña, soldado del capitan Ceron", a quien atribuye la indicación a los turcos de que debían batir el castillo de arriba hasta destruirlo, lo cual facilitó luego que "arremetieran por allí los infieles" el día del combate definitivo. Y como se resiste a admitir esa felonía en un español, escribe a continuación: "Yo creo seria algún esclauo, porque tal vellaqueria no cupiera en ningún español natural" ${ }^{35}$.

${ }^{33}$ Para el caso de la pérdida de Rodas, GONZÁLEZ CASTRILLO, R., "Sobre la conquista otomana de Rodas", Anaquel de Estudios Árabes, 18 (2007), pp. 127-129.

${ }^{34}$ SANDOVAL, op.cit., p. 376a.

${ }^{35}$ ROCCA, op.cit.,f. CXI rb. 
López de Gómara, por su parte, habla de la información que facilitaron a Jayr al-Dīn dos moriscos granadinos huidos de la plaza, respecto a "quan flacos, desmayados y heridos estaban los de dentro y que no era fuerte ni difícil de tomar ya el castillo porque la artilleria habia allanado ya la mayor parte de los reparos y albarradas que habían hecho" ${ }^{36}$. Esta información le decidió a continuar el cerco cuando, quizá, lo habría levantado, deprimido como estaba por los muchos daños que estaba recibiendo durante el asedio ${ }^{37}$.

\section{DESASTRE FINAL}

A los "tres o quatro días" de la escaramuza protagonizada por Machín de Munguía, sigue narrando el esclavo que tuvo lugar un nuevo encuentro entre los sitiados y los turcos, con suerte favorable para los primeros que "boluieron victoriosos a Castilnouo, en cuyas murallas colgaron muchas cabeças que cortaron a los turcos". El 5 de agosto salieron de sus bastiones "hasta tres mil o quatro mil turcos y genizaros", que subieron por la muralla "que estaua derrocada", pero los defensores dieron buena cuenta de ellos matando, entre otros, al capitán de los jenízaros. Barbarroja decidió entonces atacar con todas sus fuerzas al día siguiente [6 de agosto] y dar "el salto o batalla general a Castilnouo", de lo cual tuvo aviso Sarmiento por el mismo esclavo. Y "a las seis en amanesçiendo començaron los turcos de batir por todas partes" la plaza, entablándose una dura lucha que duró seis horas, en la que murieron "algunos christianos pero mucho mas turcos".

Reanudado el combate a la "ora de visperas", los turcos subieron a la muralla del castillo, precedidos de un gran fuego de artillería, y tomaron el "turrion grande y dos torres grandes biejas que estauan en el", causando muchos muertos a los cristianos. Contraatacaron éstos pero, superados en número, hubieron de retirarse "a la plaça mayor de la tierra". Al "dia siguiente [7 de agosto] en amanesçiendo" Francisco Sarmiento ordenó a los soldados que quedaban con vida que se aprestaran para el combate definitivo. Y lucharon con tal ímpetu que "los turcos entraron tres vezes en la plaça y otras tantas fueron rebotados della por los christianos". Pero, finalmente, acabaron sucumbiendo ante el gran número de enemigos, y los pocos que sobrevivieron buscaron refugio en "otro castillejo viejo que estaua caue la muralla de la marina", cuyas puertas intentaron romper los turcos para pasar a todos los refugiados "por hilo de espada", pese a que "los christianos les echaran la ropa y dineros que tenían y se rendían a Varbarosa".

El conflicto terminó cuando el corsario intervino pidiendo a los jenízaros que le entregasen siete de las personas que estaban dentro del castillo a cambio de "quinze

\footnotetext{
${ }^{36}$ Reparo: fortificación pasajera, como atrincheramiento, obra del momento o de campaña. Albarrada: defensa, parapeto, barricada levantada de improviso. ALMIRANTE, J., Diccionario Militar, Madrid, Ministerio de Defensa, 1989.

${ }^{37}$ LÓPEZ DE GÓMARA, op.cit., p. 428.
} 
mil ducados". Aceptado este trato, "Barbarossa saco la gente que estaua dentro y la repartio en sus galeras", quedando finalizada así la reconquista turca de Castelnuovo, pero no el relato de este esclavo quien continúa dando noticias acerca de las intenciones de Barbarroja de conquistar Cátaro y Mesina, que ocupan un folio más.

Pese a lo extenso de su relato y la minuciosidad de que hace gala en ocasiones, el esclavo narrador deja algunos puntos oscuros que es preciso aclarar acudiendo a otras fuentes. La crónica de Sandoval es la que aporta mayores y más concretos datos. Señala, por ejemplo, las fechas de las seis batallas que se dieron: el 24 y el 25 de julio, festividad de Santiago, y los días 4, 5, 6 y 7 de agosto. El último de estos días era jueves y en él murieron Francisco Sarmiento y los capitanes Sancho de Frías y Juan Vázquez, luchando bravamente "espaldas con espaldas y rodeados de cuerpos que ellos auian muerto". Y precisa que Castelnuovo "fue batido y combatido veynte y dos días con sus noches a la contina", que murieron "casi todos los ianizaros y diez y siete mil turcos y morlacos, aunque muchos quentan que fueron treinta y siete mil", y que perecieron todos los españoles a excepción de unos "ochocientos de toda suerte de gente, contando las mujeres y moços". El cuerpo de Francisco Sarmiento no fue reconocido entre la cantidad de muertos que había. Y en cuanto a Machín de Munguía, Barbarroja "le rogo" que abrazara el Islam y, al negarse a ello, "le mando degollar en el espolón de su galera"

El relato del esclavo huido a Venecia que hemos venido comentando, no fue el único referido por un testigo presencial de la pérdida de Castelnuovo. Manuel Fernández Álvarez da cuenta de haber consultado otro, aportado por "dos soldados de la compañía del capitán Vizcaíno, los cabos de escuadra Juan de Alcaraz y Francisco de Tapia", en copias manuscritas que se conservan, respectivamente, en el Archivo de Simancas y en el del Reino de Bruselas ${ }^{39}$. Y aun debe incluirse en este apartado la extensa "Relacion que envia Doria de cómo paso la presa de Castelnovo"- guardada en Simancas y que recoge Laiglesia ${ }^{40}$-, donde aporta datos y fechas que a veces no coinciden con los de otros cronistas.

Así, fija la llegada de "el auanguardia del armada turquesca" el 14 de julio. Cifra el contingente de tropas de Barbarroja en 18.000 turcos y 4.000 jenízaros, y el de sus "galeras y nauios de remo" en "hasta 200, y antes mas que menos". Menciona la traición de un artillero que informó a Barbarroja de cuál era la parte más débil del castillo alto -"porque no tenían aparejo de fortificarse ni repararse por de dentro"donde debía concentrar el fuego de la artillería, cosa que hicieron los turcos, con el resultado de que" por alli se dio el combate principal y se perdio Castilnouo a los 7 de agosto". Precisa que las bajas turcas fueron de "hasta 3.000 y no mas, y aun diz que si

${ }^{38}$ SANDOVAL, op.cit., 377a. Para Vicente Rocca, la cifra de pérdidas turcas en los veintidós días que duró la lucha fue de 15.000 y los supervivientes españoles, 400. ROCCA, op.cit., f. CXI va.

${ }^{39}$ FERNÁNDEZ ÁLVAREZ, M.,"La gesta de Castelnuovo”, Historia 16, 111 (1985), pp. 37-42.

${ }^{40}$ LAIGLESIA, op.cit., pp. 590-596. 
creyera a Baruaroxa no murieran tantos". Y, por último, afirma que a Machín de Munguía y al obispo Jeremias les cortó la cabeza el corsario.

Algunas otras noticias sueltas acerca de Castelnuovo hemos podido espigar asimismo en documentos conservados en el Archivo de Simancas, como el testimonio de un tal Juan Balarino de Dulcino, "persona reconoscida y fidedigna", quien afirmaba el 23 de agosto [de 1539] que después de la caída de la plaza "escaparon hasta dozientos soldados y otros capitanes y que Barbaroxa dio por que no los degollasen los genizaros 5.000 ducados". Añade, además, que "Francisco Sarmiento y Lazaro [de Coron] son vivos... avnque bien heridos" ${ }^{41}$.

Otro testigo presencial de lo ocurrido fue Galaz de Moscoso, alférez de la compañía de Pedro de Sotomayor, que fue hecho esclavo después del desastre y escribió unas escuetas líneas el 11 de agosto desde "dentro de Castilnouo", notificando que "muchos sargentos y alferes estan en poder de Barbaroxa" y que Machín de Munguía había sido decapitado "en entrando en la galera". Aseguraba además que Sarmiento, Vizcaíno y Sancho de Frías estaban muertos ${ }^{42}$.

El mismo documento que recoge las noticias del alférez Moscoso, incluye también las facilitadas por cierto "capitan Nicolo" el 14 de agosto, referentes al combate que padeció Castelnuovo el 6 de dicho mes "por mar y por tierra", en el que sufrieron los turcos la "perdida de millares dellos" por el efecto de "vna mina de poluora que los nuestros hizieron". La lucha se reanudó al día siguiente, a las tres horas, en medio de "vn temporal de admirable agua y de viento" que fue "la causa de la perdida de Castilnouo, porque la mina de poluora que los nuestros hauian tornado a hazer, ni la artillería ni la arcabuzeria no pudo obrar por respecto del agua" ${ }^{\text {43. }}$.

En consecuencia, "cinco mil genizaros y infinita otra gente de turcos y morlacos" asaltaron el castillo de arriba y durante más de seis horas combatieron con los defensores, muy inferiores en número. Refiere a continuación una insólita noticia, no confirmada en otras fuentes, según la cual Francisco Sarmiento, refugiado en el castillo de la marina, habría intentado pactar con Barbarroja, pero dicho pacto "no le fue obseruado y dize que esta mal herido en poder de Barbaroxa". El confidente acaba sus mensajes afirmando que el corsario "ha quemado a Castilnouo y le ha arruinado de los fundamentos", habiendo hecho prisioneros a Sarmiento "y otros xij españoles y los otros degollados". Como puede verse, pues, al término de la contienda se sucedían las noticias contradictorias.

${ }^{41}$ AGS, Guerra Antigua, leg. 15, doc. 56.

${ }^{42}$ AGS, Guerra Antigua, leg. 15, doc.52.

${ }^{43}$ Sandoval habla también de la intensa lluvia que cayó el 6 de agosto a la cual achaca asimismo la pérdida definitiva de la plaza, "porque les mato las mechas de los arcabuzes, los quales hazian la guerra y la matança". Y Rocca menciona, a su vez, la mina que hicieron los defensores, que no tuvo efecto alguno "porque es aquella tierra mouediza", pero no hace alusión a la lluvia. SANDOVAL, op.cit., p. 376b; ROCCA, op.cit., f. CXI va. 


\section{SUPERVIVIENTES}

La suerte que corrieron los supervivientes de Castelnuovo en su cautiverio fue, al parecer, bastante penosa. Miguel Angel de Bunes mantiene que Carlos V intentó por todos los medios liberarlos ${ }^{44}$. Pero es el caso que el ya citado Pedro de Urdemalas, protagonista del Viaje de Turquía, asegura haber visto en Constantinopla cuando estuvo allí en 1556 -es decir, diecisiete años después de la pérdida de aquella plaza- "a muchos pobres españoles" que permanecían todavía cautivos. E incita al monarca a "rescatar todos los soldados que alla hay", a sabiendas de que "el Rey ni lo ha de hazer ni aun ir a su notiçia" 45 . Bien es cierto que, en apoyo de la Corona, es preciso señalar que los rescates en Constantinopla eran prácticamente inexistentes, ya que ni los frailes Mercedarios ni los Trinitarios "nunca pisaron dicha ciudad", como asegura Serrano y Sanz ${ }^{46}$.

Pero que Carlos $\mathrm{V}$ procuró rescatar a los cautivos de Castelnuovo, es algo confirmado documentalmente. Y lo hizo, además, a los pocos meses de la pérdida de la plaza, mediante negociación con el propio Barbarroja a través del contador Juan Gallego, quien había sido comisionado por Doria y Gonzaga para tratar con el corsario de su posible entrada al servicio del Emperador. Cuestión ésta bastante discutida que constituye, al decir de Fernández Álvarez, "uno de los capítulos más oscuros de la época imperial" y a la cual se refiere como "un supuesto intento por Barbarroja de pasarse al servicio imperial" ${ }^{47}$.

El ms. misceláneo núm. 783 de la Biblioteca Nacional de Madrid, con letra del siglo XVI, confirma dichos tratos. Incluye, entre otros documentos, un escrito del propio Carlos V redactado en Gante a 3 de marzo de 1540, que ocupa los ff. $3 \mathrm{r}_{\mathrm{r}}-6_{\mathrm{v}}$, donde indica que el negociador Gallego debía comunicar a Barbarroja que había de "soltar y poner en libertad a todos los christianos captiuos que houiere en sus galeras de los que se perdieron en Castelnouo y en la naue de Villegas de Figueroa".

Tan prioritaria era la liberación de esos cautivos que, de no acceder Barbarroja a lo solicitado, el contador quedaba facultado para ofrecer por ellos un rescate de "treinta o hasta quarenta ducados de oro por cada vno", encareciéndole que en este asunto "haueys de trauajar todo lo posible por todas las vías y maneras que os pareçieren conuincentes de manera que aya effecto".

Andrea Doria indica, además, al mediador que recuerde al corsario los siete arraeces $^{48}$ que él personalmente le envió y libere a cambio los catorce cautivos de

${ }^{44}$ BUNES, M. A., "Las sensaciones del cautivo, psicología y reacciones de los españoles ante el cautiverio en el Siglo de Oro”, Hispania Sacra, 51 (1999), p. 566.

${ }^{45}$ GARCÍA SALINERO, op.cit., p. 250.

${ }^{46}$ SERRANO Y SANZ, Manuel, Cautiverio y trabajos de Diego Galán, Madrid, Sociedad de Bibliófilos Españoles, 1913, p. XX.

${ }^{47}$ FERNÁNDEZ ÁLVAREZ, M., "La España del Emperador Carlos V”, en MENÉNDEZ PIDAL, Ramón (dir.), Historia de España, Madrid, Espasa, 1966, t. XVIII, pp. 562 y s.

${ }^{48}$ En el f. 2v se indica que fueron nueve los arraeces enviados a Barbarroja. 
Castelnuovo cuyos nombres se mencionan, entre ellos, el capitán Maxquefa, el obispo, el pagador Hernando de Molina, el alférez de Francisco Sarmiento y también al genovés Juan Gentil, apresado con anterioridad en una galeota. Los documentos referidos muestran, pues, bien claramente, el interés de Carlos V por liberar a los cautivos de Castelnuovo, manifestado con reiterada insistencia en el curso de los tratos que venía manteniendo con Barbarroja. De ahí que sorprenda el reproche de Pedro de Urdemalas, protagonista del Viaje de Turquía, que consignamos anteriormente y la desconfianza que encierran sus palabras hacia la conducta del Emperador ${ }^{49}$.

\section{CONCLUSIONES}

El heró́smo y arrojo de los defensores de Castelnuovo, que en número harto reducido resistieron sin desmayo a enemigos muy superiores, fueron encomiados por cuantos escritores trataron del tema. Diego de Haedo, discutido autor de la Topographia e Historia general de Argel ${ }^{50}$, refiere que "Chereddin degollo a quatro mil españoles, todos soldados viejos y muy valientes que el Emperador auia puesto alli en guarnicion debaxo el gouierno de Francisco de Sarmiento, maestre de campo muy valeroso, el qual tambien murio con ellos, combatiendo muy valerosamente"

A su vez, el autor del Viaje de Turquía pone en boca del protagonista Pedro de Urdemalas la afirmación de que "despues que en el mundo hay guerras, nunca hubo mas valerosa jente ni que con mas animo peleasen hasta la muerte que tres mil y quinientos soldados que alli se perdieron" ${ }^{52}$.Y sus palabras no provienen de haber presenciado personalmente este suceso sino que le fueron transmitidas por los propios turcos, para quienes Castelnuovo estaba "en cabeza de todas las hazañas que en tiempos ha habido, y a esta postponen la de Rhodas" ${ }^{33}$. Que el sacrificio de estos héroes estuviera justificado, en términos prácticos, es otra cuestión.

\footnotetext{
${ }^{49}$ Véase, supra p. 83.

${ }^{50}$ Tradicionalmente ha venido considerándose autor de esta obra al benedictino fray Diego de Haedo, abad de Frómista, a cuyo nombre están expedidas las licencias de impresión. Va dedicada a su tío y homónimo el obispo de Palermo, Presidente y Capitán General del Reino de Sicilia, quien la compuso -afirma- recogiendo las informaciones de cautivos cristianos de Argel y cuyo borrador entregó a su sobrino para que le diera forma y preparase su publicación. No obstante, George Camamis opina que el verdadero autor fue, probablemente, el Dr. Antonio de Sosa, compañero de cautiverio de Cervantes, y que debió escribirse entre los años 1577 y 1581. CAMAMIS, G., Estudios sobre el cautiverio en el Siglo de Oro, Madrid, Gredos, 1977.

${ }^{51}$ HAEDO, D. de, Topographia e historia general de Argel, Valladolid, Diego Fernández de Córdoba y Oviedo, 1612, f. 60v.

${ }^{52}$ GARCÍA SALINERO, op.cit., p. 250.

${ }^{53}$ Ibidem.
} 